\title{
テラヘルツ周波数コムの観測と分光計測への応用
}

\author{
弥永 祐樹 ${ }^{1}$, 謝 宜達 ${ }^{1}$, 坂口 良幸 ${ }^{1}$, 横山 修子 ${ }^{1,2}$, 稲場 肇 $^{3}$, 美濃島 董 $^{3}$, \\ 荒木 勉 ${ }^{1}$, 安井 武史 ${ }^{1,4}$ \\ '大阪大学大学院 基礎工学研究科 ( ₹ $560-8531$ 豊中市待兼山町1-3) \\ ${ }^{2}$ 日本マイクロ光器 ( $=610-1104$ 京都市西京区大枝中山町2-20) \\ 3産業技術総合研究所 計測標準研究部門 (†305-8563 茨城県つくば市梅園1-1-1) \\ 4徳島大学大学院ソシオテクノサイエンス研究部（テ770-8506 徳島市南常三島2-1)
}

\section{Observation of Terahertz Frequency Comb and Application for Spectroscopy}

\author{
Yuki IYONAGA, ${ }^{1}$ Yi-Da HSIEH, ${ }^{1}$ Yoshiyuki SAKAGUCHI, ${ }^{1}$ Shuko YOKOYAMA, ${ }^{1,2}$ \\ Hajime INABA, ${ }^{3}$ Kaoru MINOSHIMA, ${ }^{3}$ Tsutomu ARAKI, ${ }^{1}$ and Takeshi YASUI ${ }^{1,4}$ \\ ${ }^{1}$ Graduate School of Engineering Science, Osaka University, 1-3 Machikaneyama, Toyonaka, Osaka 560-8531 \\ ${ }^{2}$ Micro Optics Co.,Ltd., 2-20 Oe-Nakayama, Nishikyo, Kyoto 610-1104 \\ ${ }^{3}$ National Metrology Institute of Japan, National Institute of Advanced Industrial Science and Technology \\ 1-1-1 Umezono, Tsukuba, Ibaraki 305-8563 \\ ${ }^{4}$ Institute of Technology and Science, University of Tokushima, 2-1 Minami-Josanjima, Tokushima 770-8506
}

(Received March 21, 2012)

\begin{abstract}
We observed the hyperfine-structured spectrum of a terahertz $(\mathrm{THz})$ frequency comb with asynchronousoptical-sampling THz time-domain spectroscopy by extending the measured time window of the pulsed $\mathrm{THz}$ electric field by up to ten pulse periods. The observed THz comb mode, having a linewidth of 25 $\mathrm{MHz}$ and a frequency interval of $250 \mathrm{MHz}$, can be used as a precise and accurate frequency marker for broadband THz spectrum because it is traceable to a microwave frequency standard via laser control. We further demonstrated $\mathrm{THz}$ spectroscopy of sugar tablets and low-pressure water vapor based on $\mathrm{THz}$ comb, indicating that the proposed method enables high-accuracy, high-resolution, and broadband $\mathrm{THz}$ spectroscopy.
\end{abstract}

Key Words: Terahertz frequency comb, Asynchronous optical sampling, Spectroscopy, Traceability, Frequency metrology

1. はじめに

テラヘルツ $(\mathrm{THz})$ 分光に基づいたセンシング技術は, THzテクノロジーの中核技術として期待されている。し かし, 従来のTHz分光計では, 周波数スケールの不確か さが保証されていないため, 同一サンプルを異なる $\mathrm{THz}$ 分光計で計測した場合, 装置毎にTHzスペクトル形状が 異なるといった問題が発生する可能性がある。このよう な問題は, $\mathrm{THz}$ 分光センシングを国内外の産業応用分野 で幅広く展開していく上で足かせとなる．THz分光セン シングが，常に普遍的な分析能力を発揮するためには， 取得スペクトルの周波数スケールが国家周波数標準にト レーサブルである必要があるが，現状はこのようなト レーサビリティ体制が整備されていない.

フェムト秒パルスレーザー光を光伝導アンテナ (PCA: Photoconductive Antenna)や非線形光学結晶に照射する と, モード同期周波数 $f$ 逆数に等しい周期のモード同
期 $\mathrm{THz}$ パルス列が時間領域で発生する。このようなモー ド同期 $\mathrm{THz}$ パルス列は，周波数軸上ではモード同期周波 数の間隔で並ぶ櫛状のスペクトル形状を示す。このスペ クトル構造を $\mathrm{THz}$ コと呼ぶ ${ }^{1,2}$. $\mathrm{THz}$ コム, 多数の $\mathrm{CW}-\mathrm{THz}$ 波の集合体と見なすことが出来るので，THzパ ルスの広帯域スペクトル特性と CW-THz波の狭スペクト ル線幅を併せ持つ。さらに, マイクロ波周波数標準から 合成された基準周波数信号に，レーザー光のモード同期 周波数を位相同期することで, $\mathrm{THz}$ コム構成する各周 波数モードの絶対周波数を確定させることができる。し たがって，このTHzコムを $\mathrm{THz}$ 分光計測における周波数 目盛りとして利用できると,「高確度」「高分解能」「広帯 域スペクトル」を併せ持つ究極のTHz分光計が実現でき る可能性がある。我々は, このような $\mathrm{THz} コ$ ムの微細ス ペクトル構造を正確に計測する手段として, 非同期光サ ンプリング式THz時間領域分光法 (ASOPS-THz-TDS: Asynchronous optical sampling THz time-domain spectroscopy) 
に着目した ${ }^{3,4)}$ 。従来のASOPS-THz-TDSでは，単一THz パルスの電場時間波形を取得しフーリエ変換によって THz連続スペクトルを得ていた。ここで，測定時間空を 大幅に拡張すれば， $\mathrm{THz}$ パルス列の電場時間波形の取得 が可能になり，そのフーリエ変換から $\mathrm{THz}$ トルを得ることが出来る(時間空拡張型ASOPS-THzTDS)。本論文では，時間空拡張型ASOPS-THz-TDSを用 いたTHzコムの観測とその分光計測への応用について報 告する。

\section{2. 時間空拡張型ASOPS-THz-TDS}

$\mathrm{THz}$ パルスを用いた代表的な $\mathrm{THz}$ 分光法である $\mathrm{THz}$ 時 間領域分光法(THz-TDS) では, 時間遅延走査用機械ス テージの移動ストロークの制限から, 通常, 単一のTHz パルスの電場時間波形を取得する(Fig. 1 (a) 左側)。こ の電場時間波形をフーリエ変換することにより, 振幅お よび位相のフーリエ・スペクトルを取得することが可能 になるが, 単一のTHzパルスではフーリエ変換によるス ペクトル形状は連続的であり周波数コム特有の形状は観 測されない(Fig. 1 (a)右側)。一方, もしTHz電場時間波 形の測定時間空がパルス周期よりも十分に大きくするこ とが出来れば, 複数の $\mathrm{THz}$ パルスから構成された $\mathrm{THz}$ ルス列の電場時間波形が観測されるであろう（Fig. 1（b) 左側)。一定周期のモード同期 $\mathrm{THz}$ パルス列をフーリエ 変換すると, 周波数領域ではパルス周期の逆数, すなわ ちレーザー・モード同期周波数の間隔でスペクトル変調 がかかり， $\mathrm{THz}$ パルス列を構成するパルス数が増えるに つれて変調が梁くなる (Fig. 1 (b) 右側). その結果, $\mathrm{THz}$ コムの超微細スペクトル構造の観測が可能になる。しか し, 従来のTHz-TDSでTHzパルス列の電場時間波形を取 得するためには, 数メートルから数十 $\mathrm{m}$ の機械ステージ を用いた時間遅延走査が必要となり, 現実的に実現不可 能である.

そこで, 我々が着目したのがASOPS-THz-TDSであ

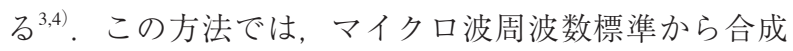

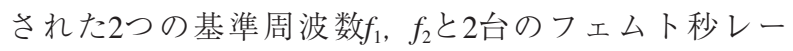
ザーのモード同期周波数を位相同期することにより，

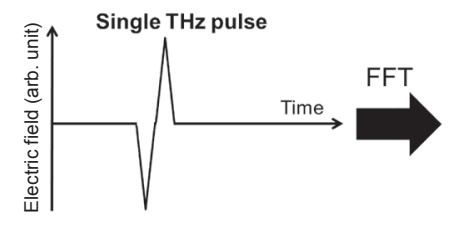

(a)

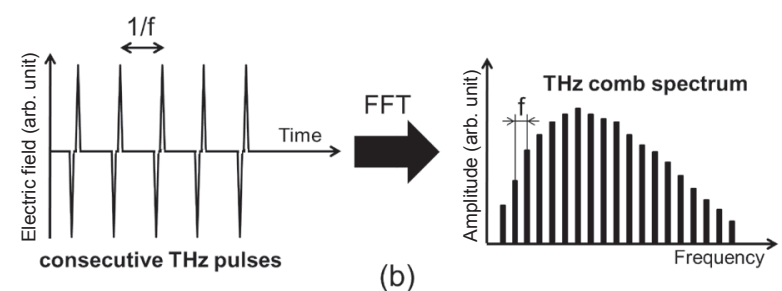

(b)

Fig. 1 (a) Temporal waveform and frequency spectrum of a single $\mathrm{THz}$ pulse and (b) consecutive $\mathrm{THz}$ pulses.
モード同期周波数をわずかに異なるように制御する (モード同期周波数差 $\left.=\Delta f=f_{1}-f_{2}\right)$ (Fig. $2(\mathrm{a})$ ). 各々の レーザー光を $\mathrm{THz}$ 発生用ポンプ光と THz検出用プローブ 光に用いると, パルス周期がわずかに異なるので, $\mathrm{THz}$ パルス (モード同期周波数 $f_{1}$ ) とプローブ光 (モード同期 周波数 $f_{2}$ ) がTHz検出素子で重なるタイミングがパルス 毎に自動的にずれていき，高速サンプリングされる (Fig. 2 (b)). その結果, サブピコ秒オーダーのTHzパル ス電場時間波形の時間スケールを，任意の時間スケール 拡大率 $\left[=f_{1} / \Delta f\right]$ で拡大できる。 マイクロ秒オーダーまで 時間スケールが拡大された $\mathrm{THz}$ パルス時間波形は, 汎用 オシロスコープで実時間測定できるので, もはや機械式 時間遅延ステージが不要となる。その結果, 測定時間空 に関する制限が解消され，任意の数の $\mathrm{THz}$ パルス列の電 場時間波形が取得できる。

\section{3. 基本特性評価}

デュアル・フェムト秒ファイバレーザー(パルス幅 $50 \mathrm{fs}$, 平均パワ $-500 \mathrm{~mW}$, 中心波長 $1550 \mathrm{~nm}, f_{1}=$ $\left.250,000,000 \mathrm{~Hz}, f_{2}=250,000,050 \mathrm{~Hz}, \Delta f=50 \mathrm{~Hz}\right)$ の出力 光を非線形光学結晶で波長变換した後, ダイポール型

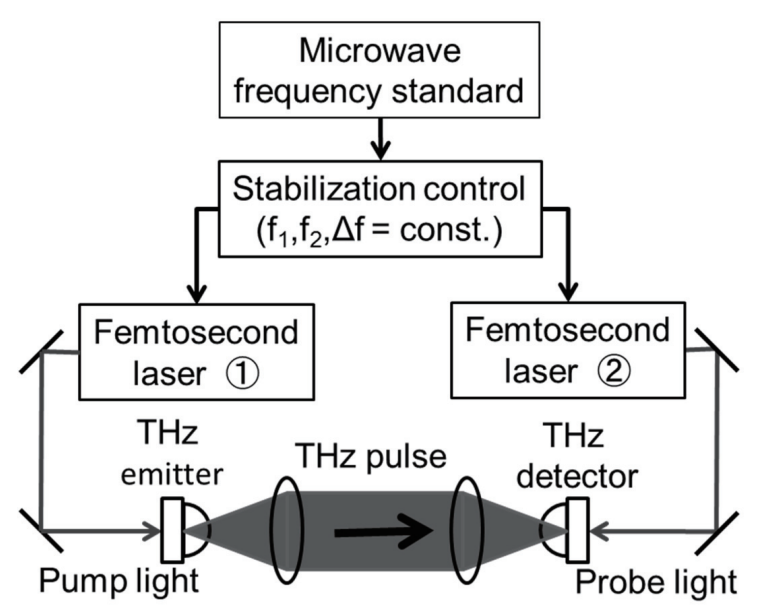

(a)

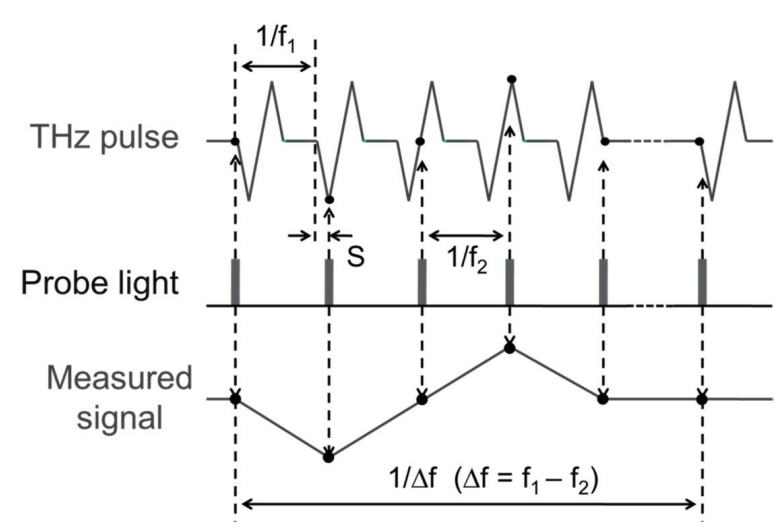

(b)

Fig. 2 (a) Schematic diagram of ASOPS-THz-TDS and (b) timing chart of $\mathrm{THz}$ pulse and probe pulse at $\mathrm{THz}$ detector. 
PCA (光伝導膜：低温成長GaAs薄膜) を用いてTHz-TDS 光学系を構築した4).ASOPS-THz-TDSの原理に基づい て, 時間スケールがRF領域まで拡大された電流信号が $\mathrm{THz}$ 検出用PCAから出力されるので, 電流電圧変換後, その時間波形を高速デジタイザーで取得した。

Fig. 3 (a) は, 測定時間密 $40 \mathrm{~ns}$ で取得した電場時間波形 を示しており，パルス周期4 nsで10連のTHzパルス列が 確認できる。従来のTHz-TDSで同様な時間波形を取得す るためには， $6 \mathrm{~m} に 及 ふ ゙$ 機械式時間遅延走査が必要にな る. Fig. 3 (b) は, 1番目のTHzパルスのメインピーク付 近(1505 ps〜1520 ps) を拡大した電場時間波形であり， サブピコ秒オーダーの詳細な THz電場の時間変化が確認 できる，次に，Fig. 3 (a)の10連 $\mathrm{THz}$ パルス列の電場時間 波形をフーリエ変換することによって取得した振幅スペ クトル (灰色) がFig. 3 (c) である。 スペクトル波形の内 部がべ夕に塗り潰されているのは，実際には1万本にも 及ぶ周波数モード列がモード同期周波数間隔で整然と分 布しているからである。比較のため, 単一 $\mathrm{THz}$ パルスの 電場時間波形 (測定時間空 $=4 \mathrm{~ns}$ )をフーリエ変換するこ とによって得られたTHz連続スペクトル(黒色)も Fig. 3 (c) に示す. THzコムスペクトル(灰色)の包絡線と $\mathrm{THz}$ 連続スペクトル(黒色)の形状は良く一致して抢り, このことはパルス周期 $(4 \mathrm{~ns})$ 以内でのTHzパルスとサン プリング光の時間遅延走查に扔けるジッターがないこと を示している。.さらに，THzコム・スペクトルの内部構 造を確認するため, $0.4 \mathrm{THz}$ 付近の周波数レンジを拡大 して示したのがFig. 3 (d) である. 線幅 $25 \mathrm{MHz}$ の周波数 モード列が， $250 \mathrm{MHz}$ の周波数間隔で分布している様子 が確認できる. 周波数間隔はレーザー・モード同期周波 数によって決定されており, 線幅は測定時間空の逆数に よって決まっている.

\section{4. 分光計測への応用}

THz ムを用いた分光センシングの有用性を確認する ため, ここではTHz指紋スペクトルを示す糖類㧍よび気 体分子の分光計測を行った。

医薬品や農薬の多くは, 各種の結晶構造に由来する特 徵的なTHz指紋スペクトルを示す上に, 結晶性変化もス ペクトルに敏感に反映されることから, 薬品類の新しい 分析手段としてTHz分光が期待されている。ここでは, 糖類(Dーマルトースまたはラクトース) $25 \mathrm{mg}$ をワイ トポリエチレン粉末 $75 \mathrm{mg}$ と混合し, 錠剤(直径 $10 \mathrm{~mm}$, 厚さ $1 \mathrm{~mm})$ にしたものをサンプルに用いた．Fig. 4 (a) は, マルトース錠剤を透過後の振幅スペクトル(灰色)を 示している，比較のため，参照錠剤(ホワイトポリエチ レン粉末 $100 \mathrm{mg}$ ) 透過後の振幅スペクトル (黒色)も合わ せて示している. 両者の比較から，1.1 THz抢よび $1.6 \mathrm{THz}$ 付近に吸収が確認できる. Fig. 4 (b) は, ラク トース錠剤㧍よび参照錠剂を透過後の振幅スペクトルの 比較(灰色抒上び黒色)を示しており，0.5 THz付近と $1.4 \mathrm{THz}$ 付近の吸収が確認できる。これらの吸収線は, 先行研究5)で報告されたTHz指紋スペクトルと良く一致
しており，本手法の有用性を示していると言える。本手 法の高スペクトル分解能特性を利用することにより, THz指紋スペクトルの形状をより瀻細に取得することが 可能になるので, THz指紋スペクトルに基づいた物質識 別能の向上に貢献すると期待される。

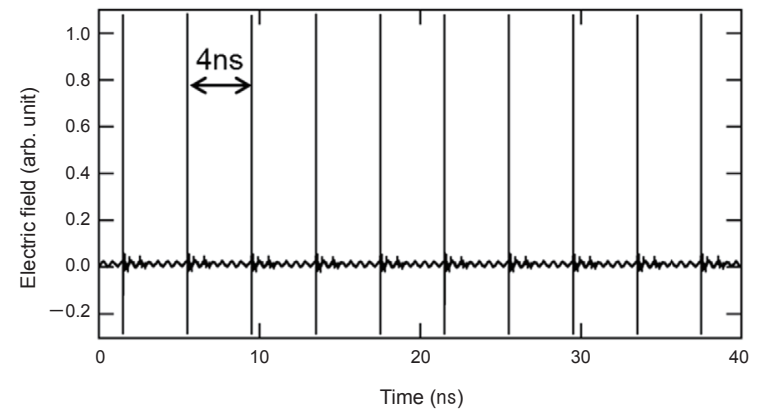

(a)

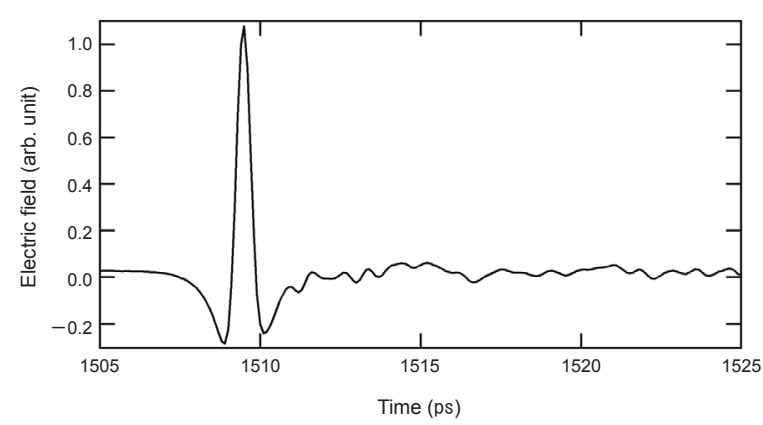

(b)

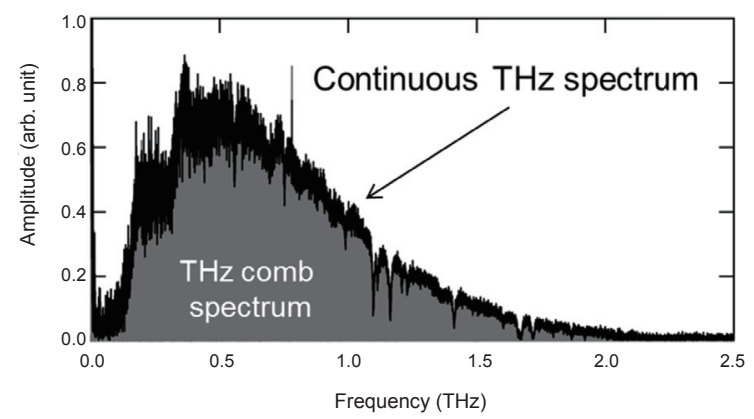

(c)

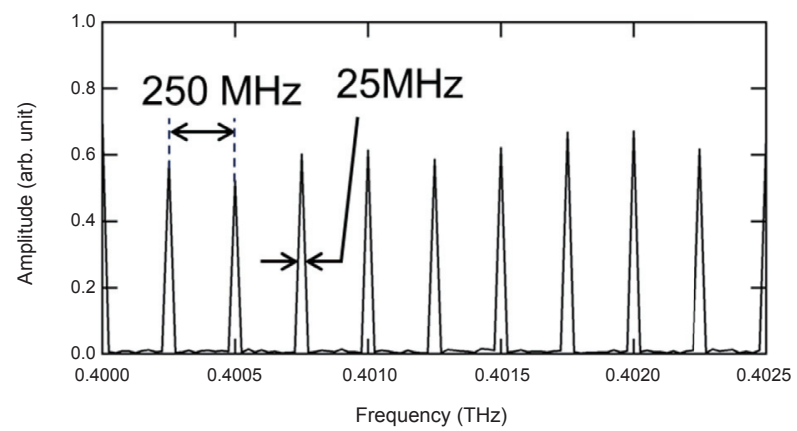

(d)

Fig. 3 Temporal waveform of electric filed in (a) 10 consecutive $\mathrm{THz}$ pulses (time window $=40 \mathrm{~ns}$ ) and (b) the first $\mathrm{THz}$ pulse(time window $=15 \mathrm{ps}$ ). (c) Comparison of amplitude spectrum between $\mathrm{THz}$ comb spectrum and continuous $\mathrm{THz}$ spectrum. (d) Detailed spectrum of $\mathrm{THz}$ comb around $0.4 \mathrm{THz}$. 


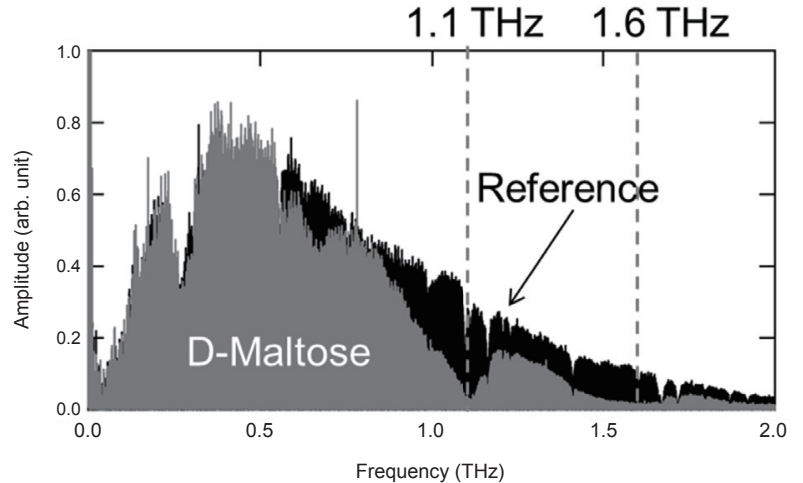

(a)

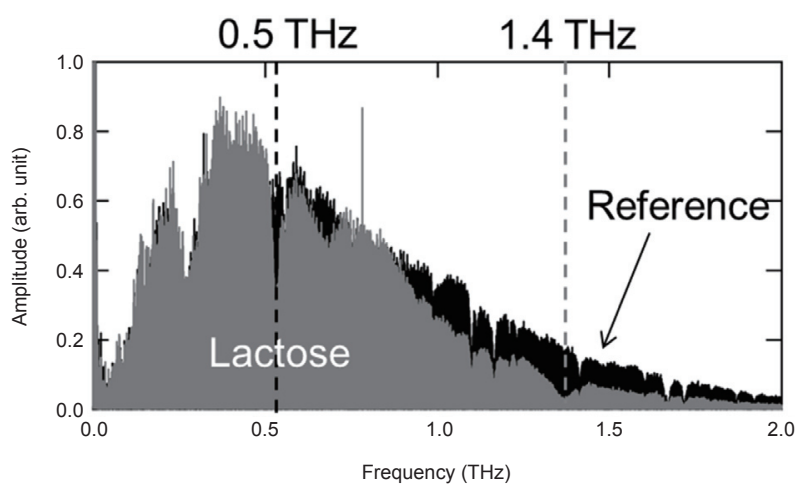

(b)

Fig. 4 Amplitude spectra of the pulsed THz electric field after passing through (a) D-maltose tablet and (b) lactose tablet (gray color). For comparison, amplitude spectra of the pulsed $\mathrm{THz}$ electric field after passing through reference tablet are indicated as a black color.

$\mathrm{THz}$ 領域は, 大気中に存在する構成原子数の少ない気 体分子の回転遷移に伴う様々な吸収線が現れる特徵的な 周波数帯でもある. $\mathrm{THz}$ 領域にひしめきあうように存在 している様々な気体分子を詳細に識別し定量するため に, 極めて高いスペクトル確度とスペクトル分解能を有 し，THz領域をフルカバー可能な分光法が望まれてい る。ここでは, 低圧状態の水蒸気をサンプルに用いて, ガス分析における本手法の有用性を評価した。水蒸気 は, 回転遷移に伴う多くの吸収線を $\mathrm{THz}$ 領域に示すこと が知られているが， $1_{10} \leftarrow 1_{01}$ 遷移による吸収線 (周波数 $0.557 \mathrm{THz}$ )を計測した。水蒸気と窒素の混合気体をガス セル (全長 $=500 \mathrm{~mm}$, 直径 $=40 \mathrm{~mm}$ ) に封入し, それぞ れの圧力を $1.5 \mathrm{kPa}$ おび $17 \mathrm{kPa}$ に設定した. この圧力条 件下に打ける水蒸気の圧力拡がり吸収線幅は $1.5 \mathrm{GHz}$ 程 度である。Fig. 5は，振幅スペクトルを示しており， $0.557 \mathrm{THz}$ 付近にシャープな吸収線が確認できる。観測 された吸収線のスペクトル幅は $1.5 \mathrm{GHz}$ であり，予測さ れる圧力拡がり吸収線幅と良く一致している。 また, 観 測された吸収線の中心周波数は0.556935999 THzであり, こちらもNASAデータベース文献值 $(=0.556936002 \mathrm{THz}$, Fig. 5の点線 $)^{5)}$ と良く一致している.

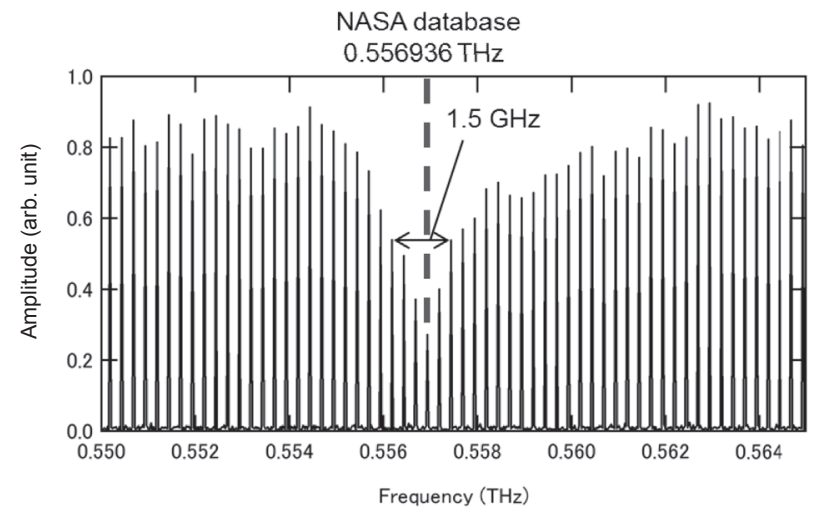

Fig. 5 Amplitude spectrum of absorption line caused by rotational transition of $1_{10} \rightarrow 1_{01}$ in low-pressure water vapor.

\section{5. まとめ}

本論文では,「高確度」「高分解能」「広帯域スペクトル」 を併せ持つTHz分光法を実現する手段としてTHzコムに 着目し, 時間空拡張型ASOPS-THz-TDSによりTHzコム の超離散マルチ・スペクトル構造を観測した。観測され たTHzコムは, スペクトル帯域 $2 \mathrm{THz}, コ ム$ 間隔 $250 \mathrm{MHz}$ ，コム線幅 $25 \mathrm{MHz}$ 有していた。ささに， $\mathrm{THz}$ コムの分光センシングへの応用例として, 糖類および気 体分子の THz分光計測を行い, その有用性を確認した. 本手法で最も重要な点は, $\mathrm{THz}$ スペクトルの周波数目盛 りとして用いているTHzコム・モードの絶対周波数が, レーザー制御を介して，マイクロ波周波数標準(今回は ルビジウム原子時計)にトレーサブルなことであり，こ れにより $10^{-5}$ 程度の不確かさで絶対周波数を付与するこ とが可能となっている。 このように，周波数スケールが 周波数標準によって保証されている $\mathrm{THz}$ 分光法はこれま で報告されておらず，THz分光センシングの高度化に貢 献すると期待される.

本研究の一部は, (独) 科学技術振興機構(JST)の研究 成果展開事業－産学共創基礎基盤研究プログラム，およ び大阪大学科学教育機器リノベーションセンターの革新 的研究教育基盤機器開発整備事業の支援によって行われ た。

\section{参考文献}

1) T. Yasui, Y. Kabetani, E. Saneyoshi, S. Yokoyama, and T. Araki: Appl. Phys. Lett. 88 (2006) 241104.

2) T. Yasui, S. Yokoyama, H. Inaba, K. Minoshima, T. Nagatsuma, and T. Araki: IEEE J. Selected Topics in Quantum Electron. 17 (2011) 191.

3) T. Yasui, E. Saneyoshi, and T. Araki: Appl. Phys. Lett. 87 (2005) 061101.

4) T. Yasui, M. Nose, A. Ihara, K. Kawamoto, S. Yokoyama, H. Inaba, K. Minoshima, and T. Araki: Opt. Lett. 35 (2010) 1689.

5) M. Schirmer, M. Fujio, M. Minami, J. Miura, T. Araki, and T. Yasui: Biomed. Opt. Express 1 (2010) 354.

6) H. M. Pickett, R. L. Poynter, E. A. Cohen, M. L. Delitsky, J. C. Pearson, and H. S. P. Muller: J. Quantum Spectrosc. \& Rad. Transfer 60 (1998) 883. 